\title{
Transport Energy Efficiency: Case of Serbia - A Review
}

\author{
Dr. Stojan Petrovic ${ }^{1}$, Dr. Velimir Patrovic ${ }^{2}$ and Dr. Vladimir Pajkovic ${ }^{3}$ \\ ${ }^{I}$ Faculty of Mechanical Engineering, Belgrade University, Serbia \\ ${ }^{2}$ Institute IMR, Belgrade, Serbia \\ ${ }^{3}$ Faculty of Mechanical Engineering, University of Montenegro, Montenegro
}

\begin{abstract}
The transport sector is one of the largest and fastest-growing energy users. At the beginning of this century the transport sector accounts for $27 \%$ of World global carbon emissions with the forecast to reach $30 \%$ in 2030. Also, the transport sector participates in total energy consumption in World $23 \%$, in EU $31 \%$ and in Serbia 22\%. The problem is that the transport still depends mainly on fossil fuels. At the same time the inefficient transport participates considerably in derogation of human environment, health and everyday life. The paper analyses energy consumption in transportation in EU and Serbia, as well as presents the measures for transport energy efficiency in EU and summarizes some possibilities of energy efficiency improvement in the transportation sector with special attention on the situation in Republic of Serbia and the possibilities for transport energy efficiency improvement.
\end{abstract}

Keywords: Energy consumption, Energy efficiency, Motor vehicles, Transport

\section{Introduction}

Mobility is one of the main characteristics of modern life. However, the intensive mobility essentially depends on comprehensive transport which enables developed economy and normal human activities. The problem is that the transport still depends mainly on fossil fuels, which are the cause for wars in the past, but also recently and in future.

The paper analyzes the role of transport in total final energy consumption and summarizes the measures for improving transport energy efficiency in EU, as well as the situation and possibilities for reducing transport energy consumption in Serbia.

\section{Energy Consumption By Transport Sector}

Average share of transport in final energy consumption in the World is about $25 \%$, in EU about $30 \%$, in Serbia about $25 \%$. Serbia is in the World average.

In 1990 the share of transport in energy consumption was only 20\%, but the share of industry was more than twice: more than $44 \%$. The share of other consumers (household, commercial and public services, agriculture, etc.) was $36 \%$. In 2002 final energy consumption drastically decreased, especially the participation of industry (Fig. 1). In that year the share of transport increased to $23 \%$, mainly because the share of industry decreased to $35 \%$, [1].

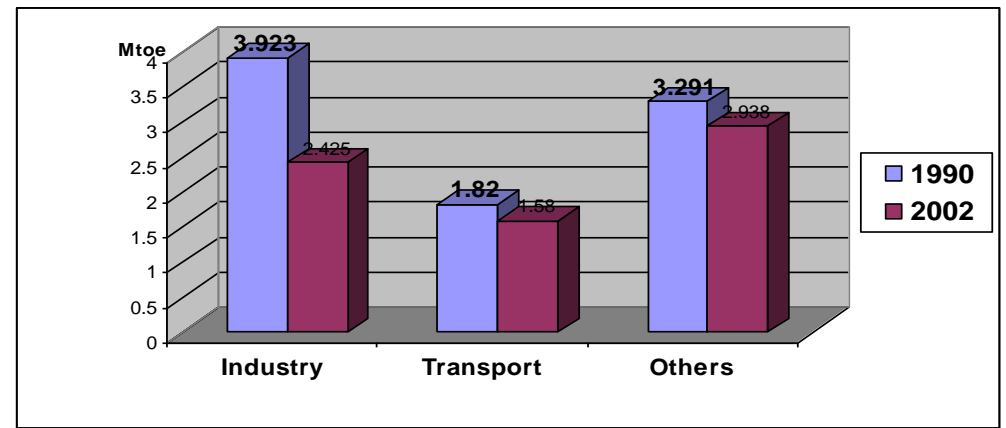

Fig. 1 The comparison of final energy consumption in 1990 and 2002, [1]

In 2010 the share of transport in final energy consumption (without non-energetic use) will again increase to $25 \%$ and the share of industry will be at $27 \%$. According to the Strategy of energy development in Serbia up to 2030, [2], energy consumption in industry will increase significantly in the future and much lower in other sectors. This optimistic forecast of future energy consumption with fast growth of industry is shown in Fig. 2. The left side of this figure shows the scenario without energy efficiency measure and on right side the scenario with energy efficiency measures is shown. Anyway, the forecast for 2030 is that the energy 
consumption of transport sector will slightly increase if the energy efficiency measures would not be undertaken and if they would be applied the energy consumption of transport will even decrease. The share of transport will be lower than in 2010., i.e. under 23\% if energy efficiency measures would not be applied and they would be applied the share of transport will be still lower, almost $21 \%$. Of course, the main reason is optimistic version that industry would have intensive growth, [2].
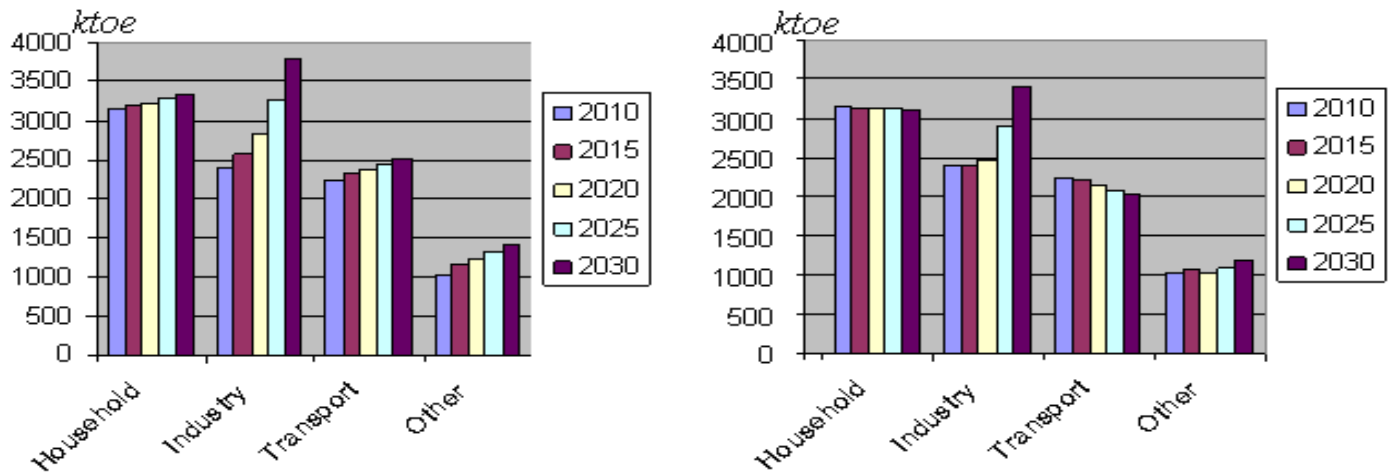

Fig. 2 The forecast of energy consumption in Serbia without (left) and with (right) energy efficiency measures

It is interesting to compare transport energy consumption in EU and Serbia. Distribution of final energy consumption by source in EU and Serbia in 2013 is shown in Fig. 3. The use of oil is the biggest in both cases, over $30 \%$, mainly because of its use in transport. As concerns the different energy sources, Serbia has bigger share in electricity and solid fuel, as well as in the use of wood for heating, but EU has bigger share in the use of oil and gas, [3].
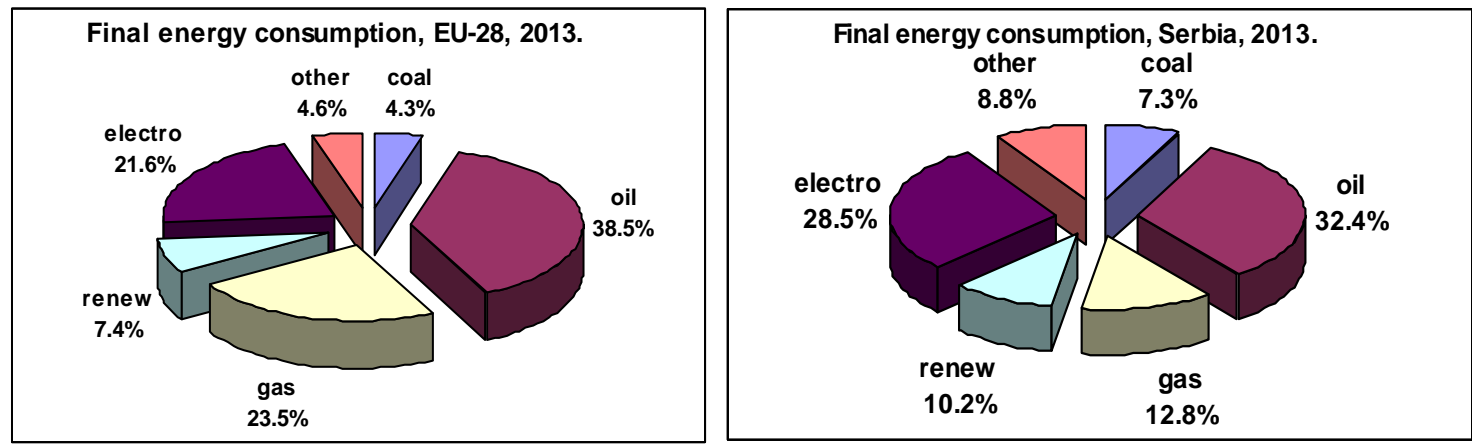

Fig. 3 Final energy consumption by source in EU and Serbia in 2013, [3]

As already said, the transport is the biggest consumer of oil. The share of transport in oil consumption is increasing and it is now over 60\%. Ten years ago, in 2004, this share was in EU 61.5\% and in Serbia 59.8\%. In 2013 the share of transport was in EU 64\% and in Serbia 61.8\% (Fig. 4).
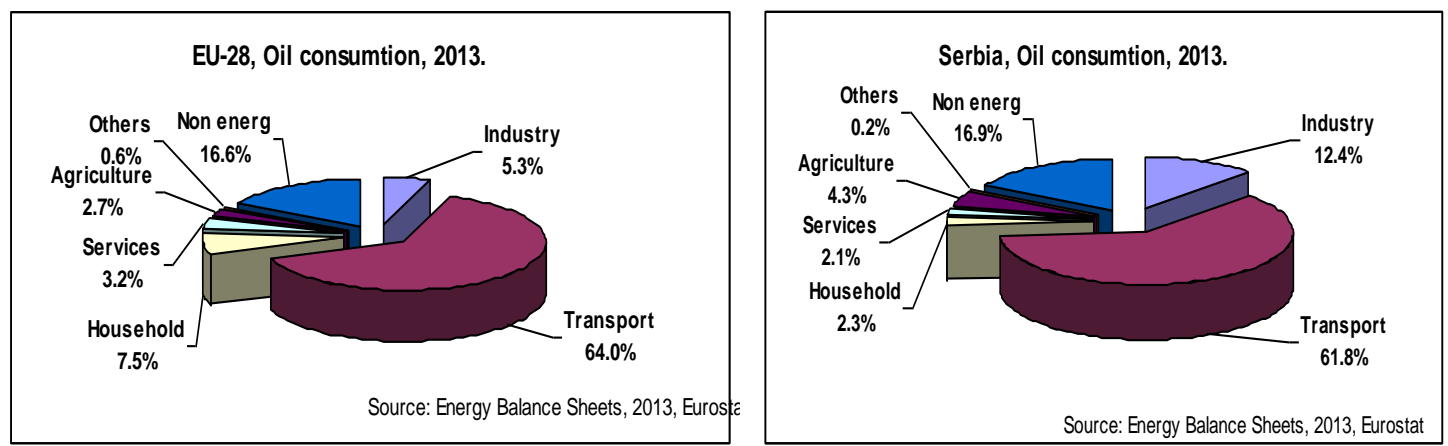

Fig. 4 Distribution of oil consumption by sectors, [3]

Transport is mainly depended on fossil fuel. In 2004 oil share in total transport energy consumption in EU was $96 \%$. In spite of EU trend to reduce oil consumption, the transport still uses $94 \%$ of oil in 2013 , mainly in road transport where oil participates with $95 \%$ in total road transport energy consumption (Fig. 5). In Serbia oil participates with $98 \%$ in transport energy consumption in 2013 and almost all is used in road transport. 


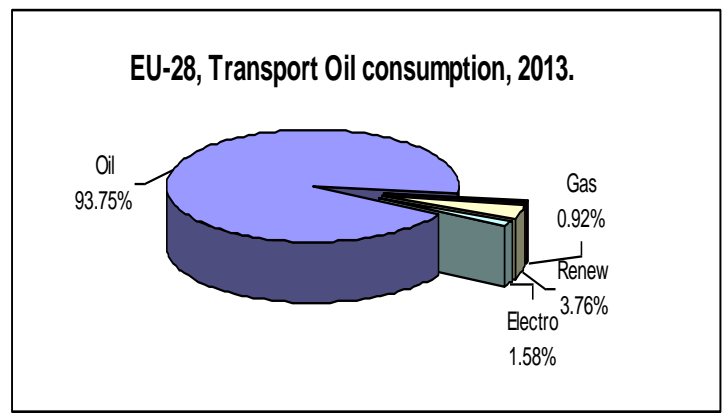

EU-28, Road Transport Oil consumption, 2013.

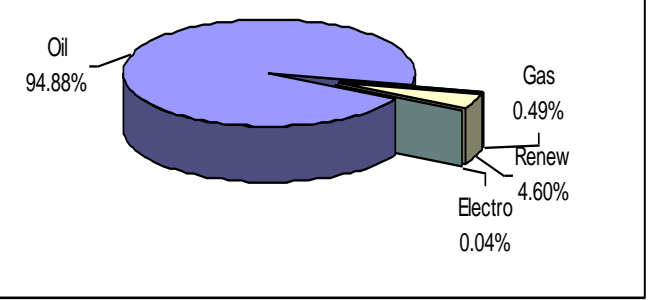

Fig. 5 Distribution of transport energy consumption by used fuel, [3]

A trend of road transport distribution of used different fuel obtained from oil is also very interesting. In 2005 the ratio of gasoline and diesel fuel used in transport in Serbia was $41.5 \%$ and $51.8 \%$ respectivly. This ratio is been now changed in favor of diesel fuel. In Serbia in 2012 the ratio of gasoline to diesel fuel was $19.2 \%$ to $63.1 \%$ and in 2013 this ratio was $18.2 \%$ to $65.7 \%$ (Fig. 6). Actually, the share of diesel fuel is increasing by $5 \%$ yearly. The ratio gasoline to diesel fuel in EU in 2013 was $21.8 \%$ to $68.8 \%$ (these ratios are bigger because of smaller average share of LPG use in EU).
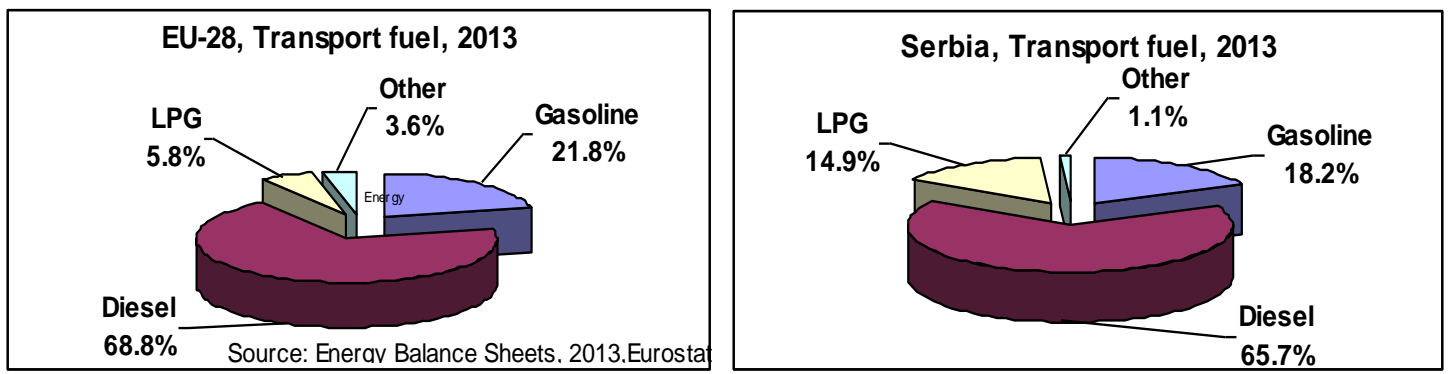

Fig. 6 Distribution of different fuels used in transport, [3]

As already said, the road transport is the biggest transport energy consumer. Road transport accounts for more than $80 \%$ of total energy consumption used by transportation (Fig. 7).
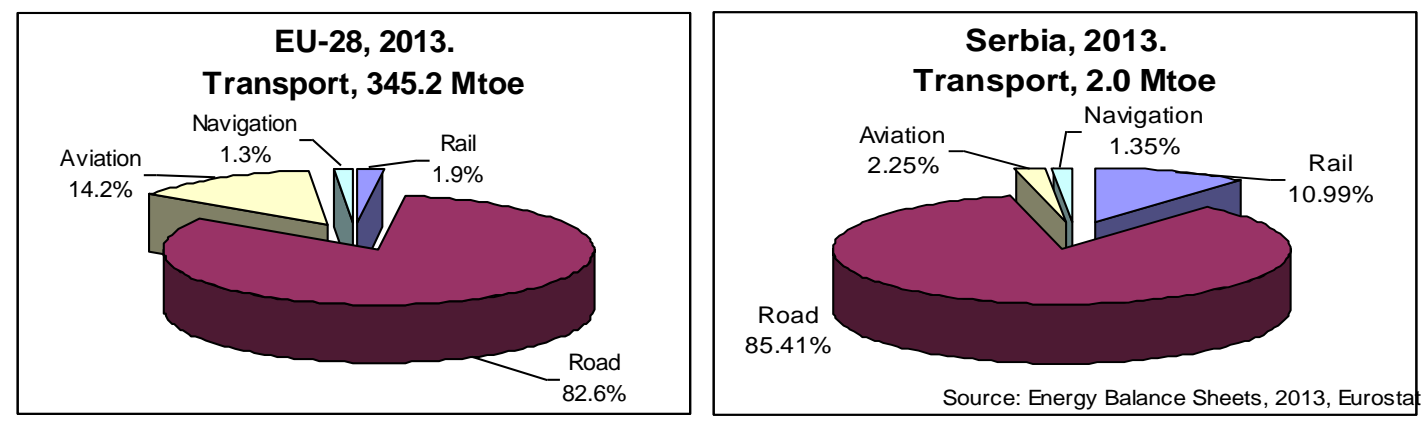

Fig. 7 Distribution of transport energy consumption by different sectors, [3]

Roughly two-thirds of transport energy is used for passenger mobility while one-third is used to move freight. Fig. 8 shows interesting transport energy distributions by different transport modes in EU in 1990 and 2004. Of course, energy consumption is increased in all modes in 2004, but it is interesting that share of aviation and LDV was increased. There is about 70 Mtoe increase since 1990 in total transport energy consumption, of which 24 Mtoe for cars, 30 Mtoe trucks and light vehicle, and 18 Mtoe for air. Also there are slight decline of road transport (from $84 \%$ in 1990 to $80 \%$ in 2004), increase in aviation (from 11 to $14 \%$, almost 30\%) and increase for goods transport (from $28 \%$ to $31 \%$ ).

Having in mind all said in this subchapter it is clear that in order to reduce the consumption of energy in transport, and primarily to reduce dependence on oil which substantially originates from abroad, it is necessary to improve the energy efficiency of transport. Question is how?

In order to improve energy efficiency in transport, a combination of different actions can be used. These actions include, [4]: 
- The improvement of transportation means;

- The improvement of traffic conditions;

- The introduction of regulatory measures.

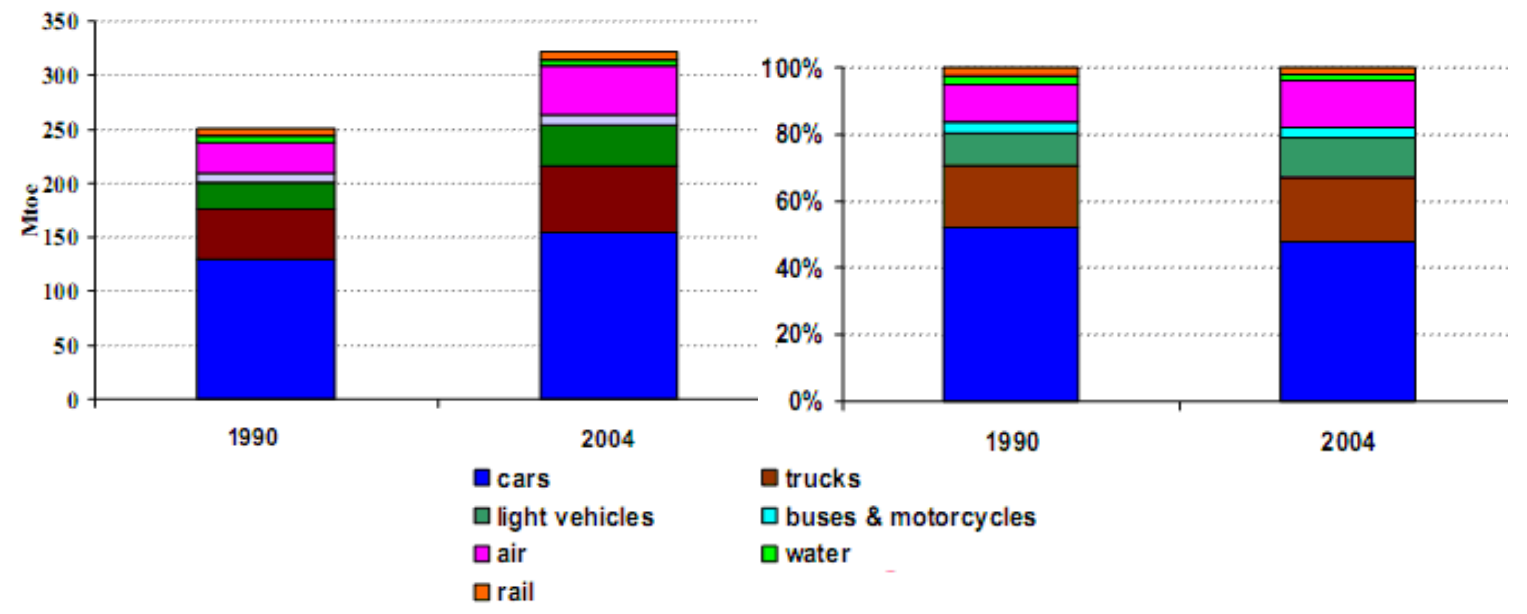

Fig. 8 Distribution of transport energy consumption by different transport modes, [4]

The improvement of transportation means includes:

- Fleet renewal;

- Improvement of vehicle energy efficiency:

- Fuel consumption and exhaust emissions reduction of conventional IC engines by the improvement of mixture formation and combustion;

- The application of high pressure turbo charging;

- The development of alternative or hybrid drive;

- The application of alternative fuels;

- The improvement of vehicle design;

- The application of efficient tires;

- The optimization of gear shifting, etc.

The improvement of traffic conditions can include:

- Modal shift - transfer from individual to public transport;

- Prevention of inefficient use of vehicle;

- Improved transport and mobility planning;

- The use of public transport;

- Better town and other spatial planning, better integration of logistical services and support for new combinations of public and private transport;

- The consumer education and ,eco driving“;

- The speed limits;

- The use of new information technologies for better logistical planning;

- The development of combined transport, etc.

The introduction of regulatory measures includes:

- The use of taxes and other pricing instruments to influence the choice of transport in favor of rail and waterways;

- Tax benefits for energy efficient trucks and cars;

- The enforcement of speed limits;

- The establishment of energy efficiency standards;

- The steady increase of energy prices, regardless of fluctuations in the price for energy sources on the market;

- Internalizing all external costs, such as environmental, pollution and health costs into transport fuel prices.

\section{EU Position On Energy Efficiency In Transport Sector}

The experience of EU in transport energy efficiency is very precious. EU EE policy in transport sector is defined in general by Directive 2012/27/EU of the European Parliament from 25 October 2012 on energy efficiency, [5]. The plan and program of measures for improvement of overall energy efficiency in EU Member States, as well as transport EE, is defined by 3rd National Energy Efficiency Action Plan (NEEAP3), [6]. This plan includes for transport 120 possible measures. These measures can be grouped in four subsets, [7]: 
- $\quad$ vehicle energy efficiency (12 measures),

- fleet renewal (36 measures),

- $\quad$ inefficient use of vehicles (46 measures), and

- $\quad$ modal shift (26 measures).

First group of measures is aiming at improving the vehicles energy efficiency. These measures are those concerning standards on energy efficient vehicles, mainly addressed to cars and voluntary agreements, also addressed now to freight vehicles.

Second group of measures is aiming at facilitating the purchase of energy efficient new vehicles. These measures include labeling, financial and fiscal policies aiming at facilitating the purchase of energy efficient vehicles and public procurement.

Third group of measures is aiming at improving the inefficient use of the vehicles, acting on the reduction of traffic congestion, improvement of driving styles, vehicle maintenance and limitation of vehicles speed.

Fourth group of measures is aiming at facilitating modal shift for both the passenger and goods modes. These measures include the infrastructural policies, as well as fiscal and informative initiatives favoring public transport.

Each EU Member State has to implement its own NEEAP according to guidelines from European Commission, [6], and to apply chosen measures. Fig. 9 shows the number of applied measures according to NEEAP3 in different EU Member States. As an example, the transport measures applied in Croatia according NEEAP3 will be shortly presented, [8]:

T.1 - Eco-driving training and promotion, 2011-2016

T.2 - Intermodal freight transport, 2014-2015

T.3 - Establishing a new payment system for the special environmental charge for motor vehicles, 2013-2016

T.4 - Promotion of integrated transport, 2014-2020

T.5 - Speed limits, 2014-2016

T.6 - Financial incentives for energy efficient vehicles, 2014-2020

T.7 - Developing an alternative fuel infrastructure, $2014-2030$

T.8 - Intelligent transport management, 2011-2020

T.9 - Introduction of special motor vehicle tax based on CO2 emissions, 2014-2020.

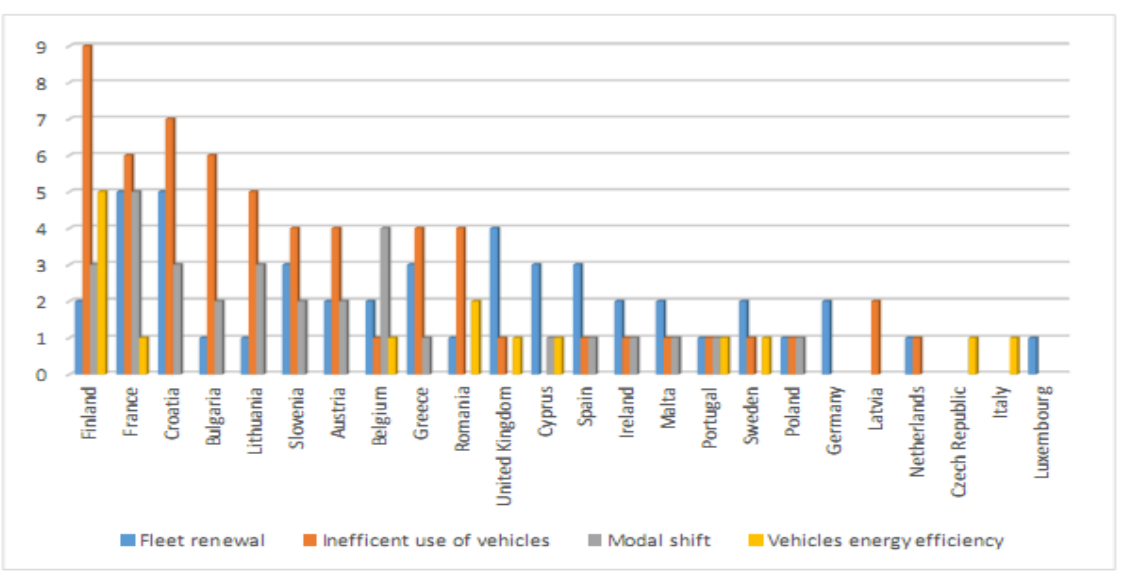

Source MURE Database

Fig. 9 Number of applied measures according to NEEAP3 in different EU Member States, [7]

\section{Situation Of EU Energy Efficiency In Transport Sector}

Before 2007 transport energy consumption had steady rise with the maximum at 2007 of about 380 Mtoe as a result of constant increase of passenger car number and intensive freight transport (Fig. 10). This maximum is a result of permanent increase of transport consumption in the main EU countries, except of Germany who had almost constant energy consumption from 1990 to 2013.

Since 2007 the energy consumption of the EU transport sector has been decreasing (by $1.6 \%$ per year from 2007 to 2013). This trend is mainly explained by a stable or decreasing consumption in the five largest EU countries: stability in Germany since 2005 and France since 2000 and decrease in UK, Spain and Italy with the economic recession (by 4.5 and $2.6 \%$ per year for Spain and Italy respectively). In spite of increased number of vehicles, this stable or decreasing consumption is a result of the introduction of measures for the improvement of energy efficiency in transport sector. 


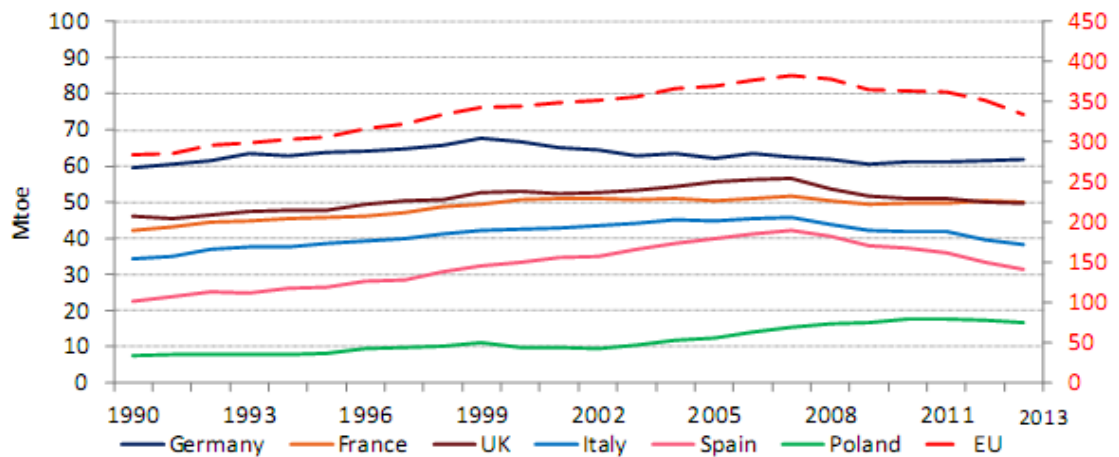

Fig. 10 Transport energy consumption in EU (right scale) and in some of its Member states (left scale)

Actually, the value of energy consumption is not real measure of energy efficiency. The increase of energy consumption can be obtained in spite of increase of energy efficiently. Unfortunately it is very difficult to find exact measure of energy efficiency, especially since it depends not only on fuel consumption, but also on vehicle mass, mass of freight, number of passengers, distance travel, etc. As a measure for energy efficiency in EU is adopted energy efficiency index measure according so called ODEX procedure.

Figure 11 shows energy efficiency index (ODEX) for final energy consumers for overall EU-27. There is total 12\% energy efficiency improvement between 2000 and 2010 (or 1.2\%/year), regular and larger gains for households (1.6\%/year), no progress for industry since the beginning of the economic crisis $(1.2 \%$ year until 2007 ) and lower progress for transport from 2007 (0.9\%/year), due to negative savings for the transport of goods since the economic crisis.

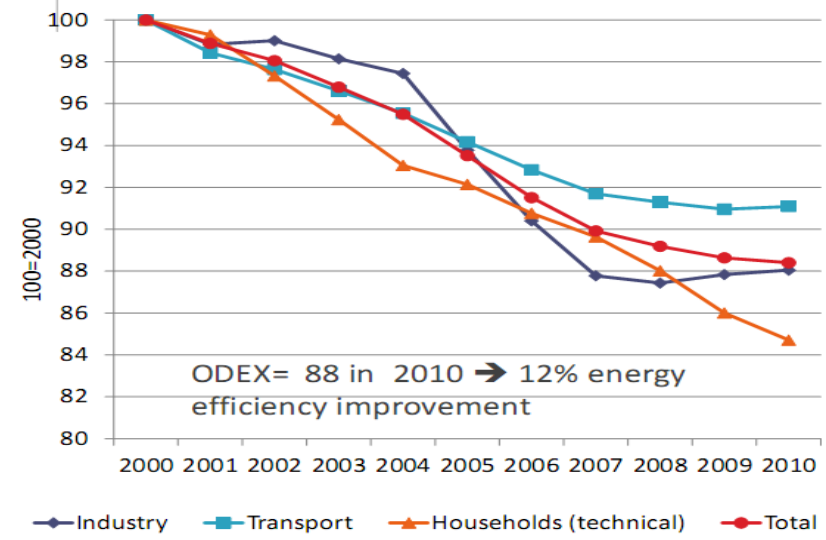

Fig. 11 Trends of energy efficiency index in EU: overall and in different sectors, [9]

Figure 12 shows energy efficiency index (ODEX) for total transport and some modes of road transport. The energy efficiency of transport in the EU improved by 1.2\%/year between 2000 and 2013, as measured according to the ODEX indicator. Greater progress was achieved in the energy efficiency of both cars and airplanes than in the rest of the sector. Energy efficiency progress slowed down for trucks and light vehicles since 2005, with no more efficiency progress since 2007 because of the economic crisis.

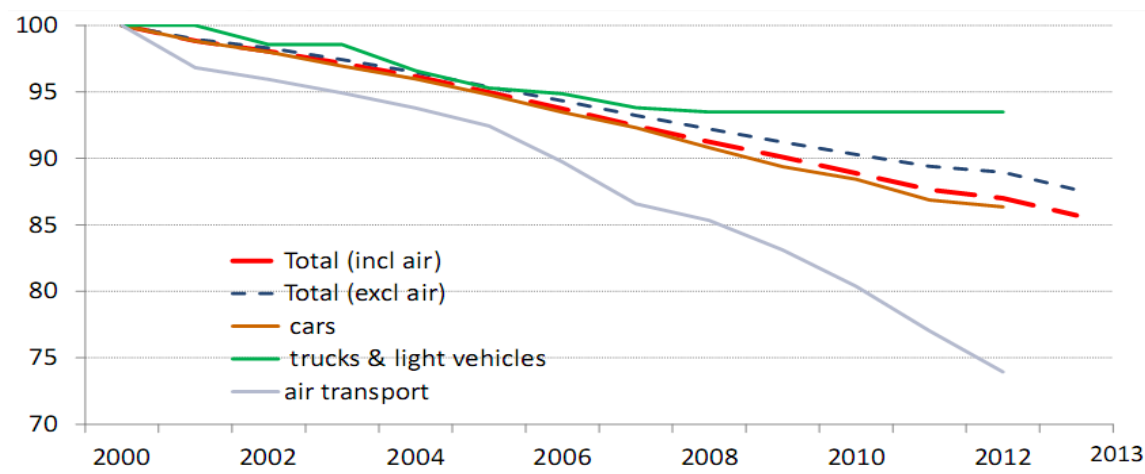

Fig. 12 Trends of energy efficiency index (ODEX) in different transport modes, [9] 
Figure 13 shows the improvement of energy efficiency index in EU countries in the time period from 2000 to 2013. There are discrepancies in energy efficiency gains in EU countries: from around 2.5-3\%/year in Greece and Latvia to $0.5 \%$ year in Lithuania and Bulgaria and almost no savings in Luxembourg and Romania. Unfortunately there is not such data for Serbia since it does not precipitate in Odyssee - Mure project.

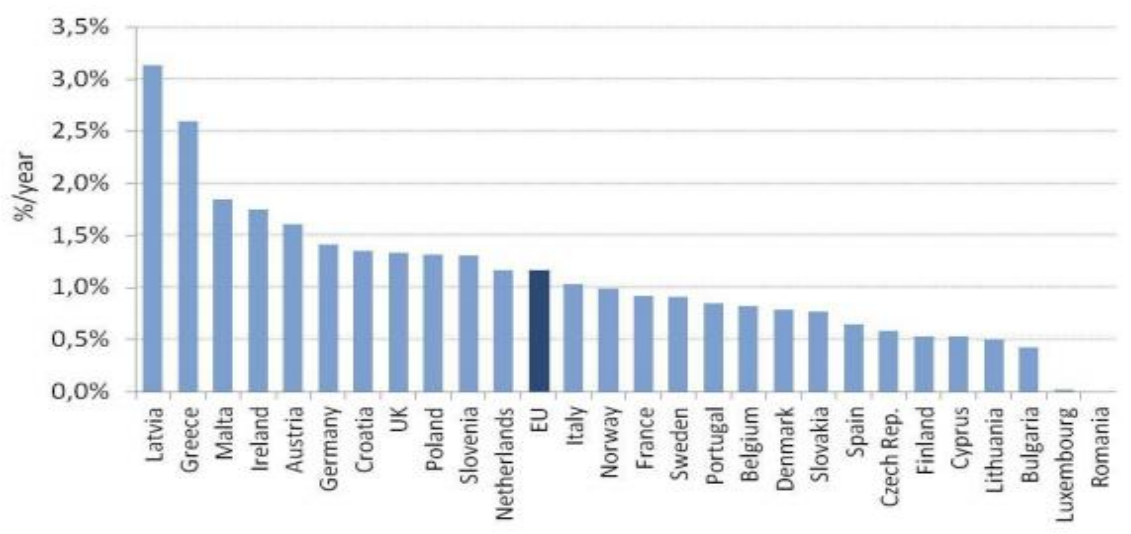

Fig. 13 Improvement of energy efficiency index in different EU countries, [7]

\section{Transport Energy Efficiency In Serbia}

The unfavorable energy efficiency in the transport (though there are not official data) is the result of several factors, [4]:

- Unfavorable age structure of both passenger and commercial vehicles (road - 15 years, rail - 31, ship - 37, air - 24 years);

- Use of vehicle outdated technologies (leaded petrol, diesel D2, EURO 2/3 etc.);

- Uncontrolled and often illegal import of foreign cars of dubious origin and technical condition (especially true for the last decade);

- Use of defective vehicles;

- Failure to comply with factory instructions on use and maintenance of vehicles;

- Bad, improper and irregular maintenance of vehicles;

- Low traffic culture of road users;

- Inadequate travel distance of the vehicle use;

- Lack of awareness of drivers on rational use of vehicles;

- Poor technical control and customer service, etc.

The traffic conditions are very often the cause of the decreased energy efficiency:

- undeveloped, outdated and inefficient road network,

- use of inappropriate infrastructure (especially in central cities, some of which are from the nineteenth century),

- lack of appropriate major arteries and bypass roads major cities,

- inadequate traffic management technology,

- frequent traffic congestion despite the low level of motorization (number of cars per 1000 inhabitants is only 244, almost half of EU average) and so on.

Adopted Energy Development Strategy until 2015, [1], has included also the measures to improve the energy efficiency of transport:

- Defining, identifying and adopting a national strategy on development of transport systems including:

- Program of transport infrastructure development program;

- Program of development of a unique and efficient transport system;

- Program of development of integrated passenger transport in urban, suburban and intercity traffic;

- Program of traffic safety including the reduction of negative environmental impact, and

- Program of the introduction of information systems.

- Alignment and harmonization of regulations in the Republic of Serbia with the EU.

- Share of energy from renewable sources in transport (10\%) in 2020.

- Increasing energy efficiency in railway, road and air transport, as well as the multi-sectorial coordination and development of transport infrastructure, promotion and improvement of public transport, etc.

- Renewal of the fleet in all sectors. Incentives for purchasing new cars and discourage the use of vehicles older than 15 years. Reducing taxes on imports of certain categories of new, smaller cars and credit to stimulate new car sale from domestic production. 


\section{Conclusion}

The transport sector participates considerably in total energy consumption with share similar as industry and household. However, the transport still depends mainly on fossil fuels, which are the cause for wars in the past, but also recently and in future. Problem is that the inefficient transport (with its CO2 emission, toxic exhaust emissions, noise, etc.) participates considerably in derogation of human environment, health and everyday life. The importance of transport energy efficiency is increasing.

To achieve improvements in energy efficiency of transport in Serbia it is necessary to:

- Implement adopted national strategy on transport energy efficiency.

- Accept European norms, procedures and best practice in this field.

- Create the conditions for the use of more rational forms of transport.

- Adopt special acts on the stimulation of energy efficient vehicles.

- Improve the conditions of public transport in order to ensure efficient transport of people and goods.

- Ensure the development and implementation of modern systems for traffic monitoring and control.

- Create conditions for the application of alternative fuels.

- Intensify scientific research and development work to improve the energy efficiency of transport.

\section{References}

[1] Strategy of Energetic Development of the Republic of Serbia up to 2015, Official Gazette of the Republic of Serbia, No. 44/2005 (in Serbian), 2005.

[2] Strategy of Energetic Development of the Republic of Serbia up to 2025 with the Projection up to 2030, Official Gazette of the Republic of Serbia, No. 111/15 (in Serbian), 2015.

[3] Energy Balance Sheets - 2013 data, EUROSTAT Statistical Book, Edition 2015 (Publications Office of the European Union, Luxembourg).

[4] S. Petrovic, Energy Efficiency in Transport, EU Sustainable Energy Week, Society of Thermal Engineers of Serbia, 2012. (On line at: http://www.drustvo-termicara.com/resources/files/de95f3e.pdf)

[5] Directive 2012/27/EU of the European Parliament and of the Council of the European Union on energy efficiency, Official Journal of the European Union, L 315, 2012.

[6] Guidance for National Energy Efficiency Action Plans, SWD (2013) 180 final, (European Commission Staff Working Document, 2013).

[7] S. Faberi, L. Paolucci, B. Lapillonne, and K. Pollier, Trends and policies for energy saving and emissions in transport, Odyssee Mure, 2015. (On line at: http://www.odyssee- mure.eu/publications/br/energy-efficiency-trends-policies-transport.pdf)

[8] The Third National Energy Efficiency Action Plan of the Republic of Croatia for the Period from 2014 to 2016 , Ministry of Economy, 2014. (On line at: http://ec.europa.eu/ energy/sites/ener/files/documents/2014_neeap_en_croatia.pdf)

[9] B. Lapillonne, and K. Pollier, Energy Efficiency Trends in Transport in the EU, Odyssee - Mure, Enerdata, 2015. (On line at: http://www.odyssee-mure.eu/publications/ efficiency-by-sector/transport/transport-eu.pdf) 